\title{
Chronic low back pain as a biopsychosocial disease: time to change our point of view
}

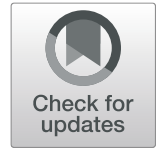

\author{
Arturo Cuomo ${ }^{1}$, Marco Cascella ${ }^{1 *}$, Alessandro Vittori ${ }^{2}$ and Franco Marinangeli ${ }^{3}$
}

Despite a plethora of available analgesic treatments, chronic low back pain (cLBP) remains the most frequent cause of disability worldwide $[1,2]$. It is usually associated with multiple comorbid conditions also affecting the psychological component, such as depression, panic and anxiety disorders, and sleep disturbances [3]. Furthermore, taken together, this heterogeneous group of clinical conditions is accompanied by a significant socioeconomic burden in both high- and low-income countries. Consequently, despite the multiple guidelines on the subject [4], effective cLBP management has multiple gaps. These gaps are probably attributable to the paradox - on PubMed, a rough search with the words "low back pain" yielded 42,279 results - of poor knowledge about the pathophysiology, clinic, and epidemiology of the phenomenon and to health policies that, probably, require appropriate changes.

Although the precise pathophysiological bases of CLBP must be well elucidated, they encompass complex combinations of peripheral pathological mechanisms and different alterations of neural and brain structures [5]. Damages mostly due to degeneration processes of the intervertebral discs, facet joints, muscles, tendons, ligaments, fascia (lumbar muscle fascia), synovium, and joint capsules can produce nociceptive and/or neuropathic pain (e.g., through nerve compression). Nevertheless, mechanical compression and peripheral inflammatory factors trigger a cascade of neurobiochemical reactions. These alterations can finally induce peripheral and central phenomena of sensitization which are expressed as pain in the absence of noxious stimuli [6]. About central mechanisms, cortical, subcortical, and spinal cord areas are involved with changes in structural and functional plasticity as well as central pain modulation network

\footnotetext{
* Correspondence: m.cascella@istitutotumori.na.it

'Division of Anesthesia and Pain Medicine, Istituto Nazionale Tumori - IRCCS - Fondazione Pascale, Naples, Italy

Full list of author information is available at the end of the article
}

abnormalities [7]. Since alterations can involve different brain areas, sensory, emotional, cognitive, and behavioral elements contribute, with a different weight, to define the features of chronic pain [8].

In the lack of an exhaustive understanding of chronic pain, several theories have been formulated over the years to explain the phenomenon. In 1999, in a fascinating paper titled "From the gate to the neuromatrix," the psychologist Ronald Melzack proposed a model which led to a new notion of chronic pain [9]. Notably, in 1965, Melzack and Wall illustrated the famous "gate control theory" that firstly viewed pain as a mind-body perspective [10]. According to the concept of neuromatrix, multiple areas of the central nervous system work together to produce pain and, in turn, chronic pain does not originate from tissue damage, but from the brain itself [9]. In this view, cLBP is not considered a linear experience directly induced by sensory input, but rather it is conceived as a multidimensional process evoked by a compounded neural network [11]. In recent decades, other theories and research have been published, but the mosaic of the pathophysiology of cLBP is far from being completed.

Chronic pain goes beyond the boundaries of those who experience it. Increasing evidence suggests the major impact of cLBP on both the affected patient and his/her family and social environment [12]. Consequently, cLBP can be considered a "biopsychosocial issue" [11]. The biopsychosocial model is another paramount pain theory. Every experience of cLBP remains unique and peculiar for the single patient and evolves dynamically. In this line, the International Association for the Study of Pain (IASP) released, in 2019, the International Classification of Diseases 11th revision (ICD11). In particular, the IASP revised the classification of chronic pain and offered conceptual instruments useful for the diagnosis and the individualized management of primary and secondary chronic pain in different settings

(c) The Author(s). 2021 Open Access This article is licensed under a Creative Commons Attribution 4.0 International License, which permits use, sharing, adaptation, distribution and reproduction in any medium or format, as long as you give appropriate credit to the original author(s) and the source, provide a link to the Creative Commons licence, and indicate if changes were made. The images or other third party material in this article are included in the article's Creative Commons licence, unless indicated otherwise in a credit line to the material. If material is not included in the article's Creative Commons licence and your intended use is not permitted by statutory regulation or exceeds the permitted use, you will need to obtain permission directly from the copyright holder. To view a copy of this licence, visit http://creativecommons.org/licenses/by/4.0/. 
[13]. Interestingly, in the ICD-11, the severity of pain is rated according to three distinct dimensions namely the intensity of pain, pain-related distress, and interference with daily living. The patient rates each dimension according to a 0-10 scale (0: absent; 1-3: mild; 4-6: moderate; 7-10: severe). Hence, the pain state is given by the sequence of a 3-digit code, which allows evaluating the severities of each dimension. This strategy could induce a positive trend reversal because much of the failure in managing cLBP is probably attributable to the lack of a holistic approach to the problem.

The clinical assessment of cLBP is crucial. Given the recognized multidimensional nature of pain, it is mandatory to evolve the strategy of pain management and its aims, from the mere relief of pain intensity to the restoring of functionality and psychological well-being $[11,14,15]$. In particular, the complexity of cLBP immediately leads to the need for a multidisciplinary assessment. In daily practice, different specialists contribute to the management of cLBP including general practitioners, orthopedists, pain therapists, physiatrists, and others. Each of these healthcare providers has different objectives and experiences. In the management of cLBP, it is fundamental to properly define the specific responsibilities of each involved specialist [14].

The most important aspect concerns the therapeutic pathway. Chronic pain should be managed through a combination of pharmacological and nonpharmacological methods keeping into consideration its intensity, pathophysiology, the complexity of symptoms, the presence of comorbidity, the social context, and the duration of disease illness. In 2019, we proposed a simple and intuitive model for pain relief, defined as "the analgesic trolley" [11]. In this model, several strategies can be applied to the treatment of pain, and therefore also to cLBP, according to the specific needs of each patient and the underlying pain mechanisms [16].

Proper treatments must be planned and started early. Although it is widely accepted that early treatment of cLBP is highly important in clinical practice, the delay in initiating adequate therapy represents a great issue [8]. It is often underestimated that proper pain treatment results in improved physical and psychological well-being, and also in a recovery of functionality, with restoring of the capability to perform daily activities, increased working ability, and diminished need for other medical therapies.

Regardless of the therapeutic strategy, pain treatment must focus on restoring functionality and physiological well-being. In harmony with the World Health Organization definition of health that is intended as a "state of complete physical, mental and social well-being and not merely the absence of disease or infirmity" and other new proposed definitions [17, 18], functionality can be viewed as the ability to ambulate, function cognitively, return to work, and complete activities of daily living including the absence of mood and sleep disturbances. This point of view has paramount implications for practice, policy, and health services since the management of functional impairment in patients with chronic pain is a collection of unmet needs concerning assessment, therapy, and rehabilitation processes.

Although applying these concepts in daily clinical practice is a great challenge, the right pathway seems to be drawn. For this purpose, Scientific Societies should implement suitable strategies to structure multiprofessional protocols and enhance the training of pain specialists and other professionals. Easy to apply guidelines and practical tools useful in different care settings are needed. Finally, the Scientific Societies must promote high-impact clinical research, involving all elements of the pain care network, in a capillary way.

\section{Acknowledgements \\ The authors want to thank the members of the study groups on Pain Medicine and Palliative Care of the Italian Society of Anesthesia, Analgesia, Resuscitation and Intensive Care (SIAARTI) for their valuable contribution to all the activities planned and regularly executed in recent years.}

\section{Authors' contributions}

A.C. and F.M. have made substantial contributions to conception and design. A.V. provided key information and helped revise the manuscript. M.C. wrote the paper. The authors read and approved the final manuscript.

\section{Funding}

Editorial assistance (bibliographic search) was provided by Luca Giacomelli, PhD, and Aashni Shah (Polistudium SRL, Milan, Italy). This assistance was supported by Grunenthal.

\section{Declarations}

Ethics approval and consent to participate

Not applicable

Consent for publication

Not applicable

Competing interests

The authors declare that they have no competing interests.

\section{Author details}

${ }^{1}$ Division of Anesthesia and Pain Medicine, Istituto Nazionale Tumori - IRCCS - Fondazione Pascale, Naples, Italy. ${ }^{2}$ Department of Anesthesia and Critical Care, ARCO ROMA, Ospedale Pediatrico Bambino Gesù IRCCS, Piazza S.

Onofrio 4, 00165 Rome, Italy. ${ }^{3}$ Department of Anesthesiology, Intensive Care and Pain Treatment, University of L'Aquila, L'Aquila, Italy.

Received: 10 September 2021 Accepted: 23 September 2021

Published online: 13 October 2021

\section{References}

1. Buchbinder R, van Tulder M, Öberg B, et al (2018) Lancet low Back pain series working group. Low back pain: a call for action. Lancet https://doi. org/10.1016/S0140-6736(18)30488-4.

2. Hoy D, March L, Brooks Pet al (2014) The global burden of low back pain: estimates from the global burden of disease 2010 study. Ann Rheum Dis 73: 968-974, 6, DOI: https://doi.org/10.1136/annrheumdis-2013-204428.

3. Baron R, Jansen JP, Binder A, Pombo-Suarez M, Kennes L, Müller M, Falke D, Steigerwald I (2016) Tolerability, safety, and quality of life with tapentadol prolonged release (PR) compared with oxycodone/naloxone PR in patients 
with severe chronic low back pain with a neuropathic component: a randomized, controlled, open-label, phase 3b/4 trial. Pain Pract 16(5):600-619. https://doi.org/10.1111/papr.12361

4. Oliveira CB, Maher CG, Pinto RZ, Traeger AC, Lin CWC, Chenot JF, van Tulder M, Koes BW (2018) Clinical practice guidelines for the management of nonspecific low back pain in primary care: an updated overview. Eur Spine J 7(11):2791-2803. https://doi.org/10.1007/s00586-018-5673-2

5. Yang S, Chang MC (2019) Chronic pain: structural and functional changes in brain structures and associated negative affective states. Int J Mol Sci 20(13): 3130. https://doi.org/10.3390/ijms20133130

6. Li W, Gong Y, Liu J, Guo Y, Tang H, Qin S, Zhao Y, Wang S, Xu Z, Chen B (2021) Peripheral and central pathological mechanisms of chronic low back pain: a narrative review. J Pain Res 14:1483-1494. https://doi.org/10.2147/ JPR.S306280

7. Kregel J, Meeus M, Malfliet A, Dolphens M, Danneels L, Nijs J, Cagnie B (2015) Structural and functional brain abnormalities in chronic low back pain: a systematic review. Semin Arthritis Rheum 45(2):229-237. https://doi. org/10.1016/j.semarthrit.2015.05.002

8. Coluzzi F, Polati E, Freo U, Grilli M (2019) Tapentadol: an effective option for the treatment of back pain. J Pain Res 12:1521-1528. https://doi.org/10.214 7/JPR.S190176

9. Melzack R (1999) From the gate to the neuromatrix. Pain S6(Supplement 1): S121-S126. https://doi.org/10.1016/S0304-3959(99)00145-1

10. Pereira PJS, Lerner EA (2017) Gate control theory springs a leak. Neuron 93(4):723-724. https://doi.org/10.1016/j.neuron.2017.02.016

11. Cuomo A, Bimonte S, Forte CA, Botti G, Cascella M (2019) Multimodal approaches and tailored therapies for pain management: the trolley analgesic model. J Pain Res 12:711-714. https://doi.org/10.2147/JPR.S178910

12. Dueñas M, Ojeda B, Salazar A, Mico JA, Failde I (2016) A review of chronic pain impact on patients, their social environment and the health care system. J Pain Res 9:457-467. https://doi.org/10.2147/JPR.S105892

13. Treede RD, Rief W, Barke A, Aziz Q, Bennett MI, Benoliel R, Cohen M, Evers S, Finnerup NB, First MB, Giamberardino MA, Kaasa S, Korwisi B, Kosek E, Lavand'homme P, Nicholas M, Perrot S, Scholz J, Schug S, Smith BH, Svensson P, Vlaeyen JWS, Wang SJ (2019) Chronic pain as a symptom or a disease: the IASP classification of chronic pain for the international classification of diseases (ICD-11). Pain 160(1):19-27. https://doi.org/10.1097/ j.pain. 0000000000001384

14. Meisingset I, Vasseljen O, Vøllestad NK, Robinson HS, Woodhouse A, Engebretsen KB, Glette M, Øverås CK, Nordstoga AL, Evensen KAl, Skarpsno ES (2020) Novel approach towards musculoskeletal phenotypes. Eur J Pain 24(5):921-932. https://doi.org/10.1002/ejp.1541

15. Panella L, Rinonapoli G, Coaccioli S (2019) Where should analgesia lead to? Quality of life and functional recovery with tapentadol. J Pain Res 12:15611567. https://doi.org/10.2147/JPR.S190158

16. Coluzzi F, Fornasari D, Pergolizzi J, Romualdi P (2017) From acute to chronic pain: tapentadol in the progressive stages of this disease entity. Eur Rev Med Pharmacol Sci 21(7):1672-1683

17. Leonardi F (2019) The definition of health: towards new perspectives. Int J Health Serv 2018 48(4):735-748

18. Bradley KL, Goetz T, Viswanathan S (2018) Toward a contemporary definition of health. Mil Med 183(suppl_3):204-207

\section{Publisher's Note}

Springer Nature remains neutral with regard to jurisdictional claims in published maps and institutional affiliations.

Ready to submit your research? Choose BMC and benefit from:

- fast, convenient online submission

- thorough peer review by experienced researchers in your field

- rapid publication on acceptance

- support for research data, including large and complex data types

- gold Open Access which fosters wider collaboration and increased citations

- maximum visibility for your research: over $100 \mathrm{M}$ website views per year

At BMC, research is always in progress.

Learn more biomedcentral.com/submissions 